\title{
ATRAVÉS DAS REVISTAS E JORNAIS
}

\section{O PROBLEMA DA EDUCAÇÃO NACIONAL}

Domina hoje, em todos os setores educacionais, a idéia de que a escola é essencialmente uma instituição social, a serviço da nacionalidade. Muitos vêm nela o prolongamento do lar, pois aclara e ilumina o futuro dos jovens. Nela se consubstancia, na realidade, o reflexo da sociedade a que serve e para a qual foi plasmada. Cada país, cada época, tem a escola que merece. Cada povo a conforma, dá-lhe fisionomia característica e a modela à sua imagem. E a certeza desta assertiva ressalta do conhecimento dos sistemas educativos e das instituições escolares vigentes nos paises de tradição democrática e nos países onde predomina a ditadura sob a forma de governo.

Essa observação pode ser completada se examinarmos, bem de perto, o problema da educação da juventude. Desde logo se nota o atraso da escola, em relação à época. Esse atraso se justifica. Porque sua função consiste em transmitir ã infância e à mocidade, a herança cultural humana. Ela guarda, portanto, o passado, defendendo-o. Sua missão é conservá-lo ao abrigo das reformas destrutivas. E daí o seu dever consiste em dar às inteligências imaturas verdades amadurecidas, onde as idéias foram submetidas aos trabalhos do tempo e às pesquisas clarificadoras e definitivas.
Além da escola ser conservadora, há, ainda, o ultra-conservantismo dos pais dos alunos. Têm eles o direito, nem sempre positivo, de dizer algo a respeito da educação a ser ministrada a seu filho. Nesse ponto, muito se mostram, por vezes, intransigentes. Porisso mesmo Cournot observava: " Ê mais fácil ao Imperador Napoleão I, com toda a sua autoridade, enviar cem mil soldados a mais para os campos de batalha na Rússia ou na Espanha, que obter da confiança e da deferência das familias, mil internos a mais, para os seus liceus". Porque elas se preocupam com a educação da infância. Daí nem sempre aceitarem modificações nos sistemas educacionais. Ora, que cultura desejam os pais para seus filhos? A resposta não exige muito raciocínio. Evidentemente, querem para eles a educação recebida e julgada a melhor, pela experiência, diante dos resultados obtidos. Julgam-na valiosa, para todos os efeitos. E hostis às inovações, as famílias permanecem como guardiãs e conservadoras do "statu-quo", defendendo-o.

Dai se conclui que a escola é, tradicionalista por natureza, e conservo-dora por necessidade. As forças progressivas tendem a impeli-la para a frente, afim de colocá-la dentro do tempo e do ritmo sociais; todavia, as forças da tradição a seguram, a detêm e a conservam. Muito embora as instituições escolares acompanhem a 
curva da história político-social do povo, nem sempre elas descrevem a mesma parábola, dentro da mesma fase temporal, porque, entre as primeiras e a segunda há, para distanciá-las, uma pausa especial necessária. Necessária para atenuar, nos espíritos a amplitude das ondulações sociais, mais ou menos intensas e mais ou menos profundas. E dai a escola não ser uma instituição motora, mas uma instituição-trenadora.

Ora, as reformas desagradam os rotineiros, pelas mudanças trazidas. Irritam ainda os reformadores impacientes desejosos sempre de avançar cada vez mais nesse terreno. Entre estes e aqueles se colocam os moderados. Consideram que não se muda, com facilidade, a natureza das coisas. Entre os dois. campos adversos pesam bem os prós e os contras. Para eles, uma reforma constitui grave compromisso assumido entre conservadores e dianteiros, certos porém de que, desagradam a ambos. No entanto, mostram-se ponderados em face do problema. Quase sempre a sua atuação se limita a ajuntar aqui, a cortar além, a mudar a dosagem das matérias, a modificar processos, sem alterar, de muito, na extensão e a profundidade, o sistema educativo, cujas linhas mestras se alteiam sobre os alicerces da estrutura social existente. Resumem-se, quando muito, a reparações contínuas ou a mudanças de peças inutilizadas. Porque, para eles, reparação quer dizer conservação e continuidade. E daí se limitarem a reformas julgadas imprescindíveis. Porisso mesmo se olharmos de cima e do alto uma reforma, verificamos logo que se trata, na realidade e no conjunto de um reajustamento da escola às necessidades sociais. Todas as reformas procuram não se afastar muito das outras anteriormente feitas. Seu rumo segue, em linhas gerais, o sentido já traçado. Lon- ge de se contradizerem, de se oporem, de se destruírem, elas se confirmam e se continuam. E assim, se examinarmos bem o edifício das instituições escolares veremos que as reformas bem orientadas lhe têm deixado intacta a economia geral porque não lhes atingiram a constituição interna. Assim ao atentarmos para o caminho seguido pelas nossas instituições escolares, através das reformas, verificamos que elas avançam na mesma direção aberta e palmilhada pelas instituições políticas e sociais existentes em nossa terra. Essa diretriz traçada pela sociedade brasileira para uma democracia cada vez mais estável corresponde à marcha do ensino disseminado aos adolescentes, dentro do sistema educacional vigente. $\mathrm{E}$ a última reforma obedeceu, visivelmente, aos postulados acima expostos e ao espírito, de bem servir às instituições político-sociais de nossa terra. Tudo leva a crer que amanhã, como hoje e ontem, a escola brasileira continuará a sentir a pressão da sociedade para a qual foi formada $\mathrm{c}$ a se modelar sempre à sua imagem. Se nosso país se encaminhasse para a forma industrializada da vida social, ou se o nivelamento horizontal das classes não deixasse mais lugar para os lazeres intelectuais e para os nobres trabalhos da inteligência, se ainda o estatismo invasor não permitisse mais o alto labor dos espíritos livres, a reforma estaria, não há dúvida, inteiramente desambien-tada. Outra seria. Vasada em moldes rígidos veríamos então entre nós, não a escola que convém à nossa Pátria e às nossas instituições político-sociais, mas outra, em tudo muito diferente. Teríamos a escola uniforme, ditatorial ou igualitária, máquina especial de formar cérebros em série, perfeitamente idênticos uns aos outros. No entanto, a escola onde o indivíduo forma o ca- 
ráter, onde a personalidade se apura educada para a vida, onde a mocidade se prepara para a sociedade e para a pátria, essa continua. E continua dentro do humanismo científico e da cultura científica. - TITO LÍVIO FERREIRA ("O Estado de São Paulo").

\section{O PROFESSOR E A ORGANIZAÇÃO NACIONAL}

Encerrando a aula inaugural na Faculdade Católica, do Rio de Janeiro, o professor Everardo Backheuser fixou o papel do professor na organização nacional, da seguinte forma:

"A melhor defesa de nosso país, contra tudo e contra todos, está na organização. Já Alberto Torres dissera a verdade, que " a organização é o maior problema nacional". Dela urge cuidar, pois, do tempo desse eminente sociólogo até os nossos dias, o problema se mantém com a mesma precisão assustadora de contornos.

Os técnicos de cada ramo reclamam contra o que se passa no respectivo campo de ação, o que mostra a generalidade, a gravidade, e a premência do assunto.

Pode-se portanto, sem desalentador pessimismo, afirmar que muito haverá a fazer para organizar o Brasil. Mas o primeiro passo será, sem discussão, ensinar a organizar. Não basta de fato " querer organizar", é preciso " saber" organizar. Administrar empresas particulares ou os negócios públicos não é, hoje em dia, arte empírica, mas algo de científico com estruturação consolidada por liames sólidos e lógicos. A organização racional do trabalho é hoje uma técnica que absorve as inteligências e requer conhecimentos especiais.

Se todo o trabalho exige para maior eficiência organização metódica, dentro de bases científicas, com mais forte razão os trabalhos de educação, seja •na escola, seja fora de seus umbrais.
O catedrático que dentro das universidades e escolas técnicas superiores prepara as elites dirigentes, o mestreescola que no âmbito dos estabelecimentos primários modela as massas, o professor secundário que nas escolas de ensino geral ou especializado dá retoques de aprimoramento à educação do primeiro grau e encaminha a transição para o terceiro nível, todos enfim que exercem o magistério, assumem, por isso mesmo, responsabilidades grandes no modo pelo qual cada nação se vem a formar.

O mestre, o professor, é o grande modelador da alma do povo; é o construtor do espírito nacional; é aquele que faz alto ou baixo o nível cultural da sociedade, nível cultural esse que influi decisivamente nos destinos mundiais do país como conseqüência de sua melhor organização. O mestre, em uma palavra, é aquele que " organiza a organização". EVERARDO

BACKHEUSER

("Formação", Rio).

\section{CAETANO DE CAMPOS}

Quando Antônio Caetano de Campos faleceu em São Paulo, deixando em começo o esplêndido trabalho de remodelação do nosso ensino escolar, trabalho em que se consumiu, como um abnegado, até a hora derradeira, deu " O Estado de São Paulo" notícia dessa morte que a todos consternara, acentuando da sua grande figura as linhas dominantes: " médico desvelado pelos seus doentes, cidadão exemplar, patriota modelo, republicano convicto", e, por último " fanático da instrução popular".

Teve esse homem insigne, em sua vida, dois fanatismos, que se igualavam em intensidade e eram resultantes de uma formação moral de imensa afe-tividade - o fanatismo da assistência médica, para os doentes, o fanatismo da 
assistência escolar, para os analfabetos. A ambas essas classes de moléstias consagrou, durante uma vida muito breve, mas extraordinariamente eficaz, todas as suas faculdades de inteligência, que eram opulentas mas, mais ainda, todas as suas reservas afetivas, que eram inesgotáveis.

De procedência humilde e família paupérrima, nascido em São João da Barra, no Estado do Rio, órfão de pai desde verdes anos, só encontrou nos primeiros passos a assistência de sua mãe, mulher denodada que, numa época como aquela, de dificuldades de toda a ordem, não quis o filho condenado a vegetar na cidadezinha em que viviam, e impeliu-o para longe, sabe Deus com que sobrehumanos sacrifícios, para que os pais não haviam aprendido, armar-se para as refregas da vida e ser um homem. Esse gesto resoluto daquela mulher, tão perspicaz nas suas poucas luzes, como que inspirada por uma centelha divina, não só deu o resultado de impelir para o alto $o$ filho inteligentíssimo mas, principalmente, fêz dele uma criatura de feitio modesto e com-passivo, que partilhava das dores alheias e se votava a amenizá-las e saná-las, com solicitude e com as reservas de carinho cultivadas no regaço materno.

Assim como Emerson deixou, na sua longa existência, e nos seus muitos trabalhos e locubrações espirituais, a marca de uma permanente doçura e magnanimidade, não se pejando nunca de confessar - e o fazia comovidamente que devia esse traço aos exemplos e à lembrança do ser todo suavidade de maneiras e rasgos altruísticos que fora sua mãe - também Caetano de Campos poderia atestar, na sua existência devotada ao bem alheio, que não fazia senão difundir e espalhar, praticamente, as lições que, desde o berço, no lar paupérrimo, recebera daquela mo- desta mas denodada senhora que lhe dera o ser, e tanto contribuíra para a sua formação moral e preponderantemente afetiva. E é sabido - aliás, os próprios positivistas ortodoxos o proclamam que as obras duradouras são aquelas em que entra uma parcela preponderante de bondade humana.

A vida desse remodelador da instrução pública em São Paulo, pelos dados cronológicos, é simples, clara e sem projeções; os tropeços que venceu, desde os primeiros passos, esses guardou-os ele na intimidade, tirando de cada obstáculo vencido e de cada vicissitude ultrapassada, lição e incitamento para vencer os que se lhe opusessem adiante, na penosa caminhada. Depois de um curso em colégio de Friburgo, cujos programas ele ampliava através de leituras da própria inspiração, matriculou-se na Faculdade de Medicina da Corte e ali se diplomou e doutorou em 1867. Embarcou, logo após o doutoramento, para o sul, fazendo como cirurgião militar grande parte da campanha do Paraguai. Interrompidos esses trabalhos por motivo de moléstias que comprometiam a sua precária saúde, veio para São Paulo iniciando a clínica civil na nossa Capital: - nesse ramo, não obstante já trabalharem aqui alguns médicos ilustres, dentro em pouco conquistou fama e largo prestígio, porque acudia não só à clientela da gente de curso em colégio de Friburgo, cujos valimento, que lhe assegurava fartos honorários, como à gente pobre, à gente miserável, que nada pagava e, freqüentemente, pedia ao médico, além da receita gratuita, o dinheiro para o remédio da botica.

Tempos houve em que a clínica de Caetano de Campos era a maior e a mais rendosa de São Paulo. Pelo que se sabe, na assistência aos doentes, e 
em particular com a gente desassistida de meios pecuniários, era a sua solicitude, a sua paciência, a sua generosidade sem desfalecimentos que completavam os benefícios da agudeza da penetração do clinico. O médico fazia da profissão o sacerdócio ideal que conjuga, na mesma pessoa, a sabedoria e a bondade, que dava remédio para os males corpóreos e, ao mesmo tempo, estimulava com a sua simplicidade caridosa os desalentados pela doença, in-fundindo-lhes coragem e completando, o receituário com o conforto moral que, em muitos casos, vale mais do que todas as terapêuticas, humanas.

Nesse trato com a gente pobre, pôde Caetano de Campos observar que outros males a desvastavam, entre eles o da ignorância - por falta de escolas e pelo mau e deficiente aparelhamento das escolas que então funcionavam. Ele sentiu de perto essa miséria que tanto desvalorizava o trabalho humano e que tão fundamente repercutia na nossa organização social. E, ao lado dos estudos a que o obrigava a profissão, entrou a cuidar com desvelo do problema da instrução popular.

Leu o que havia de melhor nas literaturas de países civilizados, detendo-se, principalmente, no que haviam conseguido as nações que lideravam esse movimento de emancipação espiritual - a Alemanha e a Suíça, seguidos de perto pelos Estados Unidos.

Republicano entusiasta do novo credo. enxergando no nosso atraso um dos grandes erros da monarquia, Caetano de Campos deveria ter visto com uma explosão de esperanças a abolição da escravatura negra, logo seguida pela proclamação da República. Por ambas tinha lutado bravamente, e à prática das novas instituições teria que dar como deu, todos os seus desvelos e energias. Observe-se que ele já se dedicava ao magistério para suprir as falhas e defeitos da instrução pública da era monárquica: para educar os filhos, convertera sua casa em escola e ali fazia um curso que era, por abençoada predestinação, o germe dos cursos que iria futuramente organizaria reger na Escola Normal.

Amigo íntimo de Rangel Pestana e de Cesário Mota, logo que se proclamou a República e aqui se instalou o Governo Provisório de composição trina, seguido pela nomeação de Prudente de Morais para Governador do Estado, Caetano de Campos foi indicado por Francisco Rangel Pestana aos encarregados do nosso Governo como o homem providencial, capaz de reorganizar a instrução pública e dar-lhe novos rumos e uma eficiência até então desconhecida. Prudente aceitou logo a indicação, como favor do céu; mas Caetano de Campos ainda hesitou, porque chefe de família numerosa, com encargos que tendiam a agravar-se, teria que sacrificar, senão abandonar de todo a sua clinica, e com esse sacrifício impor à família um regime de restrições, vizinhas da pobreza. Mas, ante solicitações e insistência dos amigos, aceitou a investidura - e, mediante os magros quatrocentos mil réis do ordenado que então era atribuído ao diretor da Escola, abandonou a clientela de muitos contos de réis que, em certas ocasiões, lhe dava, num dia de trabalho, o que a Escola lhe pagaria num mês!...

Assumindo aquele posto de abnegação e sacrifício, Caetano de Campos passou a trabalhar como um gigante, remodelando, da raiz à copa aquela árvore mofina que, com o seu trabalho, sob suas vistas e com a sua vigilância carinhosa de todas as horas, dentro em pouco daria conforto e sombra a todas as gerações de estudiosos que tanto 
contribuiriam para a elevação dos nossos índices de cultura e civismo.

Foi breve o período em que Caetano de Campos esteve à testa da Escola Normal menos de dois anos; mas, nesse curso lapso de tempo fêz trabalho ingente, deu a orientação inicial à instrução pública de São Paulo e comunicou, por um prodigio de magnetismo pessoal, todo o seu entusiasmo pela causa aos homens de governo. Deve-se recordar que o trabalho máximo de Caetano de Campos foi o de interessar decididamente os governantes de São Paulo pela causa da instrução, que esse homem, eletrizado por uma centelha de visionário, sabia ser a semente da nossa grandeza futura; - com esse trabalho, valorizou o professor, honrou o mestre-escola, deu a este foros e franquias que o professor jamais tivera no Brasil. Convém recordá-lo agora - e a classe dos mestres, hoje tão grande, tão prestigiosa, e tão cercada de vantagens e de acatamento deve ter isso presente às suas cogitações cotidianas - que, até o aparecimento de Caetano de Campos o professor era tido em conta de elemento secundário da nossa organização social Mestre-escola era ofício de segunda ordem, e a classe se compunha de gente de todos os matizes, em geral devotada ao ofício, animada de um sopro de espiritualidade que era vizinho do sacrifício, mas nunca posta, na gra-dação que merecia, como formadora do nosso plasma social.

Essa concepção, corajosamente exposta, sobre o papel que, na idade moderna, foi atribuída ao professor, ele a dava naquele discurso de colação de dezembro de 1890, o primeiro marco da sua vitoriosa pregação: "se a antigüidade teve como tipo ideal o guerreiro façanhudo - se a idade média preconizou o monge que pregava a cruzada, o homem moderno concretiza sua fé no modesto pedagogo".
E, no memorial que, em 1891 apresentou ao Dr. Jorge Tibiriçá deu, em linhas largas mas firmes, o esboço do que poderia ser o nosso ensino pelos tempos afora. Lendo agora essas páginas, tem-se a impressão de uma visão profética, porque tudo quanto se fêz de bom e duradouro em São Paulo, ali está, no germe inspirador de algumas linhas, e o que ainda não foi feito, também ali está claramente insinuado. Até o problema do ruralismo, que anda agora, novamente, agitado, tem ali a sua primeira semente, a solicitar o bafejo e os carinhos dos seus futuros culto-res. Percebe-se que Caetano de Campos desejava a adoção, para o ensino secundário, de um tipo da escola para a Capital e para os centros de cultura avançada, e um outro tipo mais modesto, com uma seriação diferente, para as zonas do interior. E, nisso tudo, aproveitando o que houvesse de melhor no estrangeiro - mas, insistia ele, " experimentando. adaptando, verificando o que era possível fazer", nunca copiando servilmente a lição de outros povos

Caetano de Campos teve certamente, presciência da morte próxima. Clínico de aguda penetração, sabendo ascultar a máquina humana dos seus clientes e nela perceber os menores desarranjos, sabia, com certeza, que a artério-escle-rose nele caminhava em passo acelerado, agravada, sem dúvida, por tantos choques, tantas lutas e, naquele fim de vida, pela mordente preocupação econômica da familia, que sacrificara conscientemente, para poder prestar ao serviço público a sua eficaz, mas derradeira colaboração.

Nisso foi movido por uma vocação invencível, que os jornais de então chamaram "fanatismo". Abençoado fanatismo!

Nele se misturava o fanatismo que sempre revelara na assistência aos 
doentes e miseráveis; tinha a mesma raiz, que era a da sua profunda consciência de solidariedade humana, que a mãe obscura lhe ensinara em menino e que, pela vida afora, ele tão dignamente viera apurando e enriquecendo. Desse fanatismo colhemos nós hoje todos os frutos.

$\mathrm{E}$, por isso, neste dia, que marca o do primeiro centenário do seu nascimento, elevemos nossos corações para bendizer a sua memória e apontá-lo à geração presente como um dos maiores credores das suas bênçãos e homenagens. PELAGIO LOBO (De "O Estado de São Paulo" ).

\section{CLUBES DE MENORES OPERÁRIOS}

O Clube de Menores Operários, que funcionam desde 1937, tiveram os seus serviços ampliados nestes últimos tempos. Dois novos núcleos para a prática de educação física, jogos e recreação de adolescentes operários, foram inaugurados nos bairros do Ipiranga e da Lapa. São Paulo conta presentemente com 3 clubes.

Uma das conquistas mais interessantes verificadas nessas instituições municipais é a continua elevação do nível intelectual dos jovens operários, em virtude do que muitos deles deixam o clu-be para matricular-se em ginásios, escolas de comércio, escolas profissionais e outros estabelecimentos congêneres que funcionam à noite.

A Municipalidade está realizando, assim, uma obra de verdadeira elevação da mentalidade do operário nacional, pois em contato com os seus instrutores, médicos e dirigentes, os menores sentem cada vez mais e de forma irresistível o desejo de aprender, de aperfeiçoar-se, de melhorar os seus conhecimentos gerais ou especializados.

Mas, um outro problema lhes surgiu. Acostumados à ginástica, aos esportes, e a outras atividades do programa de recreação, como biblioteca, canto coral, teatro de brinquedo, de repente tudo isso lhes veio a faltar, pois agora vão ao ginásio e não mais freqüentam o clube à noite.

Nessa situação acorrem eles a superitendência do serviço e pedem lhes seja permitido freqüentar, aos domingos e feriados, pela manhã, os parques de jogos, de sorte a poderem gozar, pelo menos em um dia da semana, das instalações esportivas e dos chuveiros esportivos que a Municipalidade lhes oferece.

Se a parte pedagógica pode ser aperfeiçoada dia a dia, a parte de instalações, no entanto, já demanda mais tempo. Há dois anos o Sr. Prefeito autorizou a construção de duas quadras de bola ao cesto para o Parque de Jogos D. Pedro II, e no ano passado, iluminação por meio de refletores para um dos campos do mesmo parque. As quadras de bola ao cesto, de solo batido com uma mistura de asfalto, fo-ram feitas pela Divisão de Vias Públicas. Poucos clubes do Brasil, mesmo os mais abastados, possuem quadras de acabamento tão primoroso como essas.

Os Clubes de Menores Operários que funcionam das 19 às 23 horas, diariamente, exceto aos sábados e domingos, são infelizmente em número muito reduzido. São apenas três e congregam mais ou menos 350 rapazes.

Mas a sua benéfica influência se estende a milhares de adolescentes operários. $\mathrm{E}$ isso devido à localização dos clubes. Muitos grupos de jogadores e esportistas acorrem de todas as partes para disputar pelejas de futebol, bola ao cesto, voleibol, pugilismo atletismo, com os sócios dos clubes.

Não é objetivo do Departamento de Cultura promover pugnas esportivas. E nunca as promove. Apenas consente que rapazes que moram longe dos clu- 
bes e não dispõem de locais para a prática de seus jogos prediletos disputem-nos com os sócios dos clubes. Raramente a permissão é negada pois o Departamento de Cultura vê dessarte a sua ação educativa largamente ampliada. Os rapazes de fora entram em um meio organizado, incomparavelmente mais elevado que o seu, e no qual a disciplina, a linguagem, os gestos são muito diferentes daqueles a que estão habituados. Disso só lhes pode resultar reais benefícios.

O interesse dos estranhos é espantoso. O Clube de Menores Pedro II é visitado anualmente por mais de 30.000 jovens, o do Ipiranga por mais de 20.000 e o da Lapa por mais de 5.000. O que já representa alguma cousa em prol da organização dos lazeres dos moços operários. - NICANOR MIRANDA ("O Estado de São Paulo").

\section{O ENSINO PROFISSIONAL E O SENAI}

No Rotary Club, o Dr. João Luderitz, presidente do Serviço Nacional de Aprendizagem Industria fèz a seguinte palestra:

(SENAI),

- O Ensino Profissional, latu senso, abrange a educação técnica de todos. adultos e menores, que pretendam exercer ou já exerçam a sua atividade na indústria, no comércio e na agricultura.

Assim, teríamos a considerar três grandes grupos da educação para as profissões: o agrícola, o comercial e o industrial.

Este último ramo de ensino será objeto desta palestra e, isto mesmo, restrito a uma de suas partes, a Aprendizagem dos Ofícios nos Estabelecimentos Industriais.

Deixando de lado qualquer apreciação histórica, não posso, todavia, furtar-me à citação de 3 nomes decisivos na evo- lução do Ensino Industrial no Brasil: o do Presidente Nilo Peçanha, que criou, em 1909, o ensino profissional oficial, no pais; e do Ministro Ildefonso Simões Lopes, que, em 1920, empreendeu a organização desse gênero de ensino dando-lhe um cunho mais técnico e o do Presidente Getúlio Vargas que, em 2 de maio de 1939, baixou o Decreto n. ${ }^{\circ} 1238$, com o que se instituiu essa forma de ensino nas fábricas, primeiro passo para a criação dos cursos de aprendizagem industrial e do SENAI.

Obedecendo ao preceito constitucional, que considera a formação racional do operariado o primeiro dever do Estado, em matéria de educação, o Ministro Gustavo Capanema elaborou, em 1942, a lei orgânica do ensino industrial, obra de envergadura notável, que traçou diretrizes seguras para essa espécie de preparo de operários.

Essa lei compreende dois grandes setores do ensino industrial: o primeiro, destinado ao preparo de técnicos especializados e de mestre de ofícios e o segundo, de qualificados. A formação de operários será feita em três tipos de cursos distintos: os cursos industriais, os cursos artesanais e os cursos de aprendizagem. Os dois primeiros funcionarão sob regime de hora integral, variando, apenas em duração e amplitude do ensino.

$\mathrm{O}$ último, destinado aos aprendizes da indústria, funcionará sob regime de horários reduzidos.

Correspondendo às diversas modalidades de ensino, previu, a lei 4 tipos de escolas: escolas técnicas, escolas industriais, escolas artesanais e escolas de aprendizagem.

Estão compreendidas no grupo das escolas técnicas e industriais as escolas federais de ensino industrial, as escolas estaduais equiparadas àquelas e as mantidas pelos municípios ou por parti- 
culares reconhecidas pelo governo da União.

Nestas condições, funcionam, atualmente, no Brasil 30 escolas técnicas e 35 escolas industriais com cerca de 14.000 alunos matriculados.

A matrícula de aluno decresce todavia, de modo impressionante das primeiras séries para as últimas, em vista das numerosas deserções durante o curso. Muitos dos menores matriculados nessas escolas, vêm-se obrigados, pelas contingências da vida, a abandonar os estudos a meio caminho, a fim de procurar colocação remunerada. Assim, não ultrapassa, em todo o país, de cerca de 500 o número dos que atualmente recebem o seu diploma de artífice, mestre ou técnico.

Ora, a indústria brasileira, em franco desenvolvimento desde 1920 e, mais acentuadamente, neste último qüinqüênio, em parte devido à guerra, já conta com um milhão e meio de empregados e, sua renovação anual, exige cerca de 8 a 10 mil novos operários qualificados, sem contar o enorme contingente de novos trabalhadores braçais e de simples manipuladores.

O recrutamento da grande maioria desses novos operários, que deverão substituir os velhos trabalhadores que se afastam, terá de ser feito, portanto, entre os menores e adultos, que procurarem emprego nas fábricas, os quais, até agora, aprendiam o seu ofício de modo mais ou menos empírico e com grande lentidão, pela observação do trabalho dos mestres e a execução de pequenos serviços auxiliares.

Com a aplicação de métodos racionais, por uma aprendizagem sistemática, segura e eficiente, sem prejuízo dos vencimentos dos menores, instituiu, a lei, as escolas de aprendizagem junto às fábricas, atendendo aos insistentes apê- los da indústria brasileira, que se prontificou, espontaneamente, a contribuir para esse fim.

A fim de organizar e administrar as escolas de aprendizagem, foi criado, pelo Decreto-Lei n. ${ }^{\circ}$ 4048, de 22 de janeiro de 1942, o Serviço Nacional de Aprendizagem Industrial, geralmente conhecido por SENAI o qual se acua subordinado diretamente à Confederação Nacional da Indústria.

A originalidade dessa organização educativa está no fato de ter sido transformada, em lei, uma oferta espontânea dos patrões, empregadores da indústria, tornando, assim, obrigatória e generalizada, não só a contribuição para manutenção do SENAI, como a admissão de determinada porcentagem de aprendizes e a sua matrícula de fre-qència às escolas de aprendizagem, durante o horário normal do trabalho, sem prejuízo dos seus meios-salários.

Inédita é, também, a delegação que fêz o Governo à Confederação Nacional da Indústria, para organizar e dirigir o SENAI, o qual é considerado. para todos os efeitos, como entidade empregadora, sujeita às leis trabalhistas.

O SENAI é administrado por um Departamento Nacional e Departamentos Regionais. O primeiro presta contas ao Conselho Nacional, constituído por delegados dos Sindicatos Patronais e representantes dos Ministérios da Educação e do Trabalho.

Nos Estados que ainda não têm $\mathrm{Fe}$ derações de Indústria instaladas, funcionam Delegacias subordinadas ao Departamento Nacional.

As organizações regionais têm caráter executivo e a nacional mantém a orientação de todo o Serviço, recebe o produto da arrecadação no Banco da Brasil e distribue recursos aos departamentos e delegacias, nos Estados, por duodécimos. 
A Divisão Administrativa do SENAI abrange os 5 departamentos regionais: Rio Grande do Sul; São Paulo; Distrito Federal e Estados do Rio e do Espirito Santo; Minas Gerais; Pernambuco, que abrange Alagoas e Paraiba. Há uma Delegacia no Paraná e Santa Catarina e outra no Ceará, atendendo esta e o Piauí, Maranhão e Rio Grande do Norte.

Para os longínquos Estados de Mato Grosso e Goiaz, Pará e Amazonas, de pequena densidade industrial, nenhuma providência pôde ainda ser tomada, dada a escassez da renda nessas unidades da Federação.

A contribuição dos patrões, para a manutenção do SENAI, foi fixada em Cr\$ 2,00 por empregado e por mês, sendo transformada, mais tarde, para maior facilidade de arrecadação do IAPI e das Caixas de Previdência, na porcentagem de $1 \%$, sobre a folha mensal de pagamento de cada empregador

A contribuição começou a ser arrecadada a partir de abril de 1942 e. neste ano, montou a 13 milhões de cruzeiros, tendo contribuído 25.000 patrões em média, com, aproximadamente, 600.000 empregados. Em 1934, elevou-se a 16 milhões de cruzeiros a receita arrecadada e, decerto, irá nesta progressão ascendente, à medida que aumentar o número de contribuintes, nesta fase de progresso vertiginoso da indústria.

O SENAI foi instalado no dia 17 de agosto de 1942, iniciando, desde logo. suas atividades.

Grandes foram as dificuldades a vencer, para implantação de um serviço dessa natureza.
A tarefa preliminar que se impunha foi o de um levantamento estatístico, destinado a averiguar o número de operários de cada ramo de indústria, bem como a sua natureza e distribuição pelos municípios, a fím de que daí pudesse ser deduzido o vulto da arrecadação e determinada a localização e o tipo das escolas de aprendizagem. Terminado o levantamento de cuja execução foi incumbido o IAPI, foram escolhidos os locais para 36 escolas de aprendizagem de diferentes tipos, desde as menores, para 100 aprendizes, até as maiores, para 5.000 alunos. Prevê, esse plano inicial, a instalação de 6 escolas para 7.800 aprendizes, no Distrito Federal e no Estado do Rio; de 14 escolas para 9.000 aprendizes, no Estado de São Paulo; de 4 escolas para 1.600 aprendizes, no Estado de Minas Gerais; de 6 para 700 aprendizes, no Paraná e Santa Catarina; de 4 para 1.600 aprendizes no Rio Grande do Sul, e de 1 em Pernambuco e outra no Ceará, para 200 alunos cada uma.

Este é o programa para 1944, pelo qual poderão ser atendidos 21.100 aprendizes e trabalhadores menores de fábricas .

Para atender à sua execução, foram obtidos, por doação, vários terrenos nos Estados do Rio Grande do Sul, Pernambuco e São Paulo.

Além desses, foram adquiridos muitos outros terrenos, no que foram gasto.-. até agora, Cr\$6.500.000,00.

Já foi iniciada a construção de prédios em Recife, Belo Horizonte, São Paulo e Porto Alegre, Nova Hamburgo e Caxias.

Para instalação dessas escolas adquiriram-se máquinas e ferramentas no valor de $\mathrm{Cr} \$$ 8.500.000,00. 